\title{
Pendidikan Kesehatan untuk Mencegah Green Tobacco Sickness Pada Petani Tembakau
}

\author{
Sri Wahyuni Adriani, Rendy Anggriawan, Muhammad Thoriq Al Imani, Andri Wahyudi \\ Universitas Muhammadiyah Jember \\ Email: sriwahyuni@unmuhjember.ac.id, Anggriawan@unmuhjember.ac.id, \\ muthoriqal@gmail.com, andriwahyudi@gmail.com
}

Diterima: Maret 2021 | Dipublikasikan: Juni 2021

\begin{abstract}
ABSTRAK
Petani tembakau berisiko tinggi mengalami Green Tobacco Sickness (GTS) karena setiap harinya mereka selalu kontak dengan nikotin yang terdapat pada tembakau. GTS merupakan gangguan kesehatan yang disebabkan keracunan nikotin pada saat memanen dan mengolah daun tembakau. Kegiatan mengolah tembakau dilakukan hampir setiap hari tanpa menggunakan alat pelindung diri sehingga menyebabkan gejala GTS diantaranya pusing, sakit kepala dan mual. Metode dalam menyelesaikan permasalahan yaitu melalui skrining kesehatan, pendidikan kesehatan tentang GTS dan pentingnya penggunaan alat pelindung diri (APD) saat bekerja mengolah tembakau, serta pelatihan penggunaan APD pada petani. Hasil menunjukkan bahwa sebagian besar petani mengalami hipertensi grade 1 sebanyak 9 orang $(39,1 \%)$, dan pre hipertensi juga sebesar 39,1\%, status gizi berdasarkan indeks massa tubuh mayoritas normal 14 orang $(60,9 \%)$, suhu tubuh rata-rata normal yaitu $36,57^{\circ} \mathrm{C}$, frekuensi nadi rata-rata normal yaitu $87,74 \mathrm{kali} / \mathrm{menit}$, frekuensi pernapasan rata-rata normal yaitu 19,48 kali/menit, gula darah acak rata-rata normal yaitu 117,91 $\mathrm{mg} / \mathrm{dl}$. Pengetahuan tentang GTS sebelum kegiatan mayoritas kurang (60,9\%), pengetahuan tantang pentingnya APD mayoritas kurang (52,2\%), perilaku penggunaan APD sebagian besar kurang $(60,9 \%)$. Setelah kegiatan terjadi peningkatan pengetahuan tentang GTS hampir seluruhnya baik $(91,3 \%)$, pengetahuan pentingnya APD baik (87,0\%), dan perilaku penggunaan APD mayoritas baik $(82,6 \%)$. Kegiatan pendidikan kesehatan efektif meningkatkan pengetahuan dan perilaku petani dalam menggunakan APD untuk mencegah GTS.
\end{abstract}

Kata Kunci: Green tobacco sickness; GTS; pendidikan kesehatan; petani; tembakau

\section{ABSTRACT}

Tobacco farmers are a group at high risk of suffering Green Tobacco Sickness (GTS) because every day they are always in contact with the nicotine in tobacco. GTS is a health problem caused by nicotine poisoning when harvesting and processing tobacco leaves. The activity of processing tobacco is carried out almost every day without using personal protective equipment, which causes GTS symptoms including dizziness, headaches and nausea. Methods for solving problems were through health screening, health education about GTS and the importance of using personal protective equipment (PPE) when working to process tobacco, and training on the use of PPE for farmers. The results showed that most of the farmers have grade 1 hypertension (39.1\%), and pre hypertension was also $39.1 \%$, nutritional status based on body mass index was normal (60.9\%), average body temperature was normal $36.57^{\circ} \mathrm{C}$, average pulse frequency was 87.74 times/minute, average respiratory rate was 19.48 times/minute, average blood sugar was $117.91 \mathrm{mg} / \mathrm{dl}$. Before healtd education, most of farmers have poor knowledge about GTS (60.9\%), poor knowledge about the importance of PPE (52.2\%), poor behavior of using PPE (60.9\%). After health education, there was an increase in knowledge about GTS, almost all of them were good (91.3\%), knowledge of the importance of PPE were good (87.0\%), most of farmers have good behavior in using PPE (82.6\%). Health education were effective in increasing farmers' knowledge and behavior in using PPE to prevent GTS.

Keywords: Farmer; green tobacco sickness; GTS; health education; tobacco 


\section{PENDAHULUAN}

Petani tembakau merupakan kelompok yang berisiko tinggi mengalami Green Tobacco Sickness (GTS) karena setiap harinya mereka selalu kontak dengan nikotin yang terdapat pada tembakau serta bahan-bahan kimia pertanian seperti pupuk dan racun hama. Petani tembakau merupakan kelompok yang berisiko tinggi mengalami GTS dengan tingkat insidensi mencapai 63,7\% (Ministry of Health, 2018). Di Kabupaten Jember terdapat 79,2\% dari 120 petani tembakau mengalami gejala GTS dengan hasil laboratorium terdapat nikotin sebesar 13,64 mg/ml dalam sampel darah mereka (Rokhmah, 2014). Khusus di Kabupaten Jember dan daerah tapal kuda yang juga memiliki hamparan penamaman tembakau, seyogyanya petani lebih mewaspadai penyakit GTS tersebut mengingat kawasan sekitarnya memiliki curah hujan yang cukup tinggi antara 1 sampai 3.394 milimeter dan kelembaban antara 61 sampai 91 persen. Padahal tembakau di kawasan tapal kuda adalah tembakau Naa-oogst yang harus dipanen sekitar pukul 05.00 pagi saat embun masih melekat di daun atau saat usai hujan dimalam hari yang sekaligus sangat rentan terkena penyakit GTS akibat kulit yang bersinggungan dengan daun tembakau basah. Faktor klimatologi inilah yang juga memberikan peluang besar petani tembakau di Jember terkena penyakit GTS.

Mitra merupakan kelompok petani tembakau yang berada di wilayah Desa Sumberwaru Kecamatan Sukowono Kabupaten Jember Propinsi Jawa Timur. Indonesia merupakan negara penghasil tembakau terbesar keenam setelah Cina, Brazil, India, USA dan Malawi, dengan jumlah produksi sebesar 136 ribu ton atau sekitar 1,91\% dari total produksi tembakau dunia(Kementerian Kesehatan Republik Indonesia, 2015). Propinsi terbesar penghasil tembakau adalah Jawa Timur. Kabupaten Jember merupakan kota yang dijuluki dengan kota tembakau karena merupakan sentra penghasil tembakau yang cukup besar khususnya di wilayah Jawa Timur. Kecamatan Sukowono juga merupakan salah satu Kecamatan yang menghasilkan tanaman tembakau cukup tinggi tiap tahunnya. Sebagai petani tembakau, mitra melakukan pekerjaan sehari-harinya di sawah, mulai dari menyiapkan lahan untuk ditanami tembakau, melakukan penyemprotan pupuk atau racun hama tembakau, mencari dan membuang ulat tembakau dengan menggunakan tangan langsung, memetik daun tembakau, dan menjemur tembakau hingga kering.

GTS merupakan gangguan kesehatan yang disebabkan keracunan nikotin pada saat memanen dan mengolah daun tembakau (Ministry of Health, 2018). GTS ini terjadi akibat penyerapan nikotin melalui kulit saat petani atau pekerja yang memetik daun tembakau saat panen di lahan sawah, terutama mereka yang tidak menggunakan alat pelindung diri. Kontak daun tembakau terhadap kulit terutama terjadi di bagian tangan, lengan, paha, dan punggung petani tembakau. Gejala seseorang yang terkena penyakit GTS ini antara lain mual-mual, sakit kepala, muntah, kulit gatal serta badan menjadi lemas (Ye et al., 2013). Gejala lebih berat seperti sesak nafas, kelelahan fisik berat sampai tidak dapat menggerakkan anggota tubuh, dan tekanan darah serta denyut nadi yang tidak stabil(Ministry of Health, 2018).

Gejala yang paling sering dialami oleh mitra diantaranya pusing, sakit kepala dan mual. Gejala tersebut dirasakan umumnya setelah seharian penuh kontak dengan tembakau. Lama keluhan yang dirasakan sekitar 1-3 hari. Kondisi tersebut terjadi karena mitra tidak ada yang menggunakan alat pelindung diri sebagai salah satu bentuk proteksi terhadap kesehatan saat bekerja (Gambar $1 \& 2$ ).
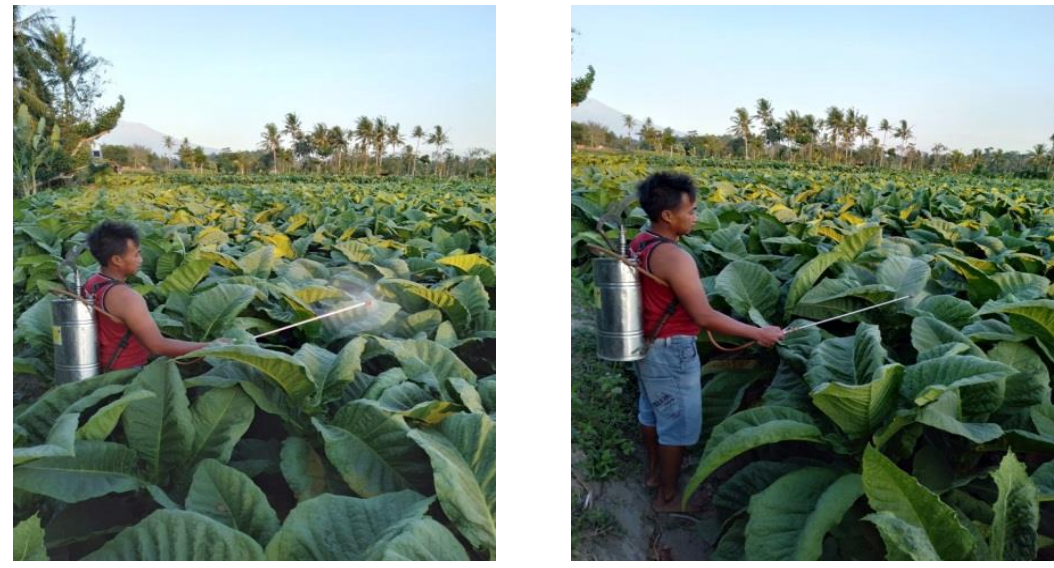

Gambar 1: Penyemprotan racun hama tembakau (tanpa menggunakan masker dan sepatu booth) 

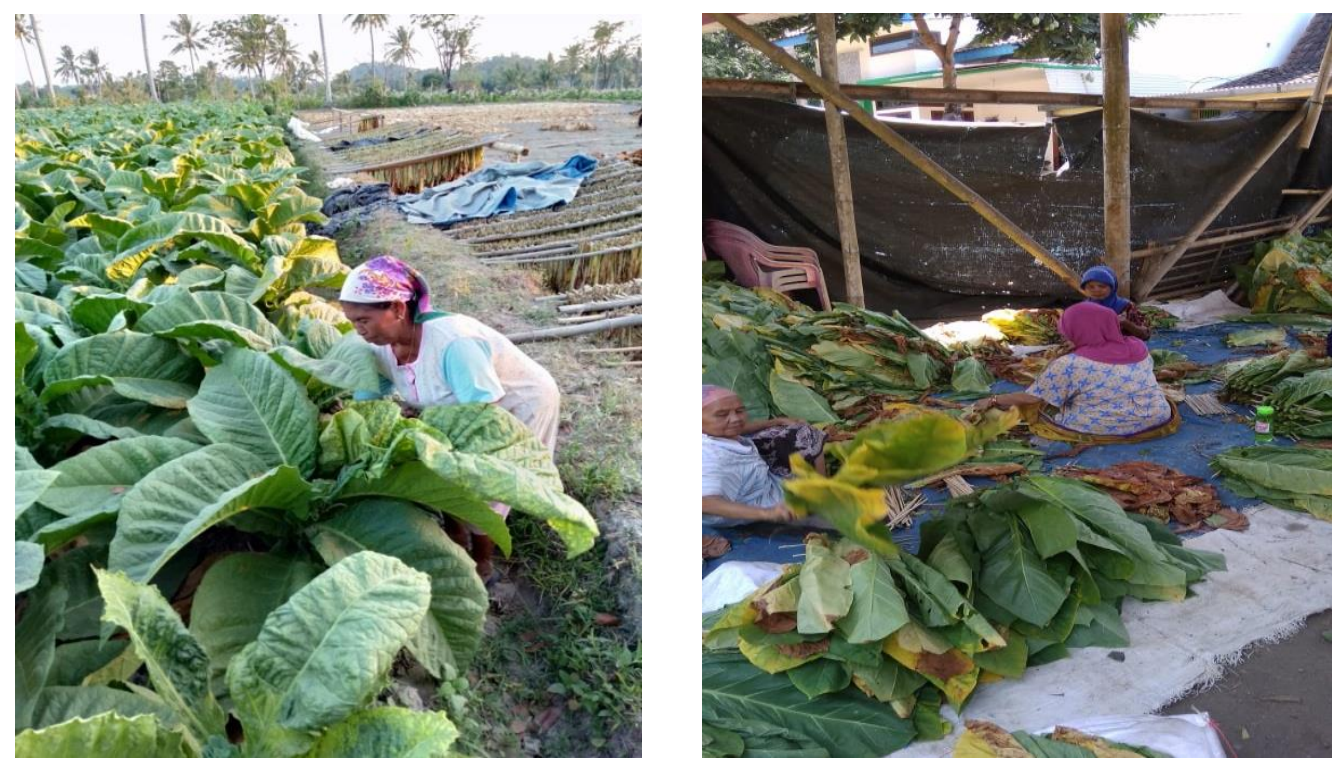

Gambar 2: Proses memetik tembakau dan memilih sesuai warna (tanpa menggunakan sarung tangan)

Gejala GTS yang dialami oleh mitra dianggap hal yang biasa dan dirasakan bukan masalah yang seirus. Mereka menganggap bahwa gejala-gejala seperti pusing, sakit kepala, dan mual yang dialami adalah hal yang biasa dan wajar karena risiko pekerjaannya mengolah tembakau. Rendahnya pemahaman mitra mengenai dampak yang dapat ditimbulkan oleh perilaku mereka dikarenakan tingkat pendidikan yang rendah. Hal ini terbukti bahwa mayoritas (80\%) anggota mitra mempunyai tingkat pendidikan rendah yaitu tamat SD bahkan ada yang tidak tamat SD. Rendahnya tingkat pendidikan ini menyebabkan kesadaran mitra akan kesehatannya juga rendah. Faktor lain yang mempengaruhi rendahnya perilaku pencegahan mitra terhadap GTS yaitu faktor ekonomi. Sebagian besar (75\%) pendapatan mitra berada di bawah UMR Kabupaten Jember karena pekerjaannya sebagai buruh tani, di mana mereka hanya bekerja untuk sawah orang lain bukan milik sendiri sehingga kondisi ini juga mengakibatkan para pekerja tidak mampu menyediakan alokasi dana khusus untuk APD selama bekerja, karena pendapatan mereka hanya cukup untuk kebutuhan hidup sehari-hari.

Permasalahan tersebut perlu segera diselesaikan untuk mencegah kondisi sakit yang berkelanjutan. Tindakan yang perlu segera dilakukan adalah meningkatkan pemahaman para pekerja bahwa perilaku mereka dapat berdampak buruk terhadap kesehatan sehingga merugikan diri mereka sendiri dan juga orang lain. Untuk membudayakan perilaku sadar terhadap keselamatan saat bekerja ini diperlukan upaya yang bertahap, salah satunya dengan meningkatkan pengetahuan mitra melalui pendidikan kesehatan, kemudian dilanjutkan dengan melatih dan melakukan pendampingan mitra tentang penggunaan alat pelindung diri saat bekerja untuk menghindari GTS.

\section{METODE PELAKSANAAN}

Metode pelaksanaan secara ringkas dijelaskan dalam alur (Gambar 3). Metode pelaksanaan kegiatan pendidikan kesehatan dilakukan melalui beberapa tahap yaitu:

1. Persiapan

Kegiatan ini telah mendapatkan surat rekomendasi dari Badan Kesatuan Bangsa dan Lindungan Masyarakat (Bakesbangpol \& Linmas) Kabupaten Jember dengan nomor 072/157/415/2021 tertanggal 2 Februari 2021. Setelah proses administratif diselesaikan, 
maka selanjutnya dilakukan koordinasi dengan ketua kelompok tani sumber rejeki sebagai mitra, terkait waktu pelaksanaan kegiatan dan mempersiapkan undangan kegiatan.

2. Pelaksanaan

Pelaksanaan kegiatan dilakukan dengan beberapa proses seperti: 1) melakukan skrining awal status kesehatan pekerja melalui pemeriksaan fisik; 2) melakukan pendidikan kesehatan tentang GTS; 3) melakukan pendidikan kesehatan tentang pentingnya penggunaan APD saat bekerja; 4) pelatihan penggunaan APD saat bekerja; 5) pendampingan, monitoring dan skrining status kesehatan secara berkala.

3. Evaluasi

Evaluasi dilakukan untuk mengetahui apakah pengetahuan dan kesadaran mitra tentang status kesehatannya saat ini sudah meningkat, pemahaman dan kesadaran mitra tentang GTS, pengetahuan mitra tentang APD, keterampilan mitra dalam menggunakan APD dan budaya kerja menggunakan APD apakah mengalami peningkatan sebelum dan sesudah pendidikan kesehatan.

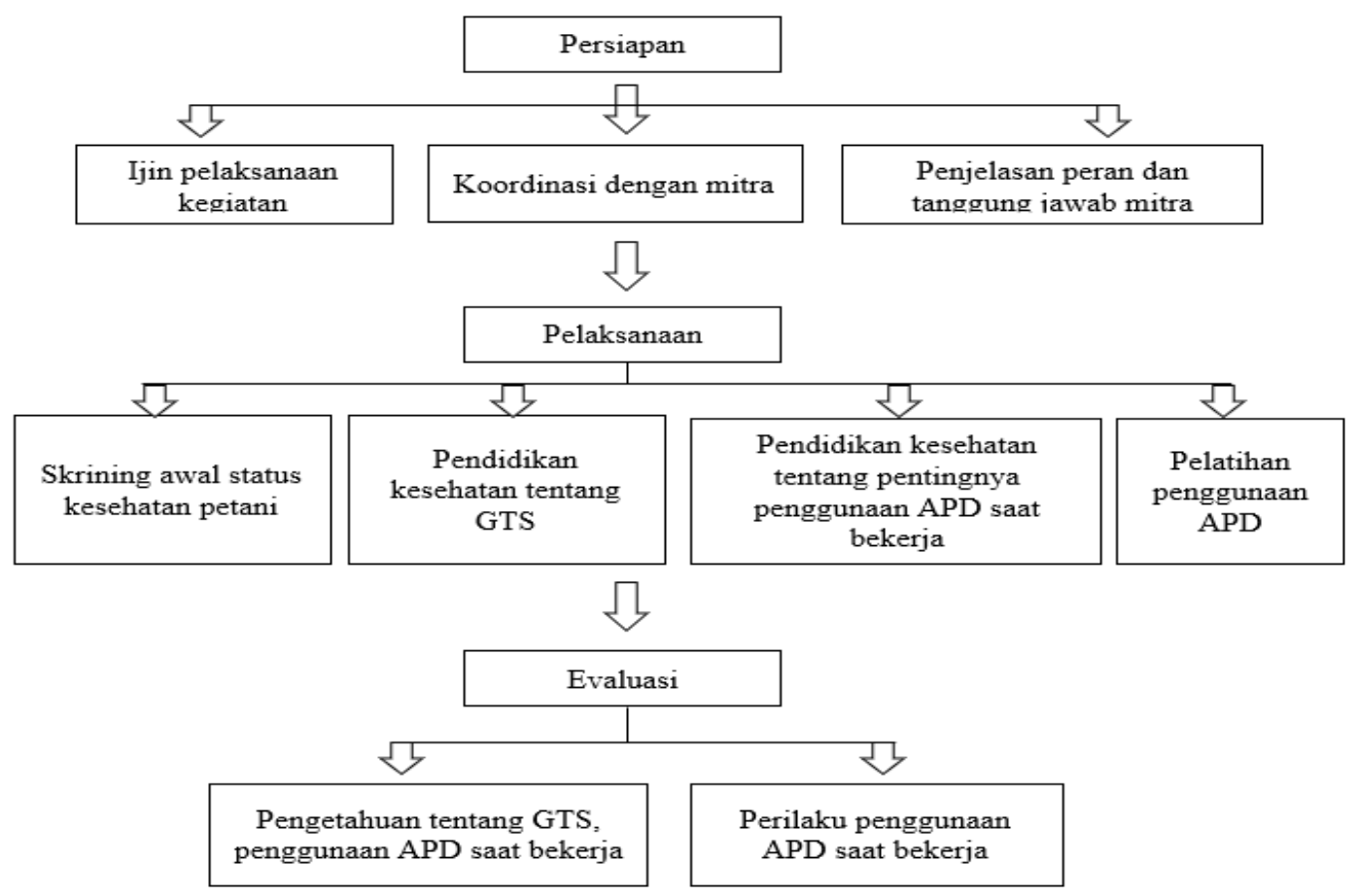

Gambar 3. Metode pelaksanaan pendidikan kesehatan pada kelompok petani tembakau

\section{HASIL DAN PEMBAHASAN}

Tabel 1 menunjukkan hasil skrining status kesehatan petani diketahui bahwa mayoritas tekanan darah petani pre hipertensi dan hipertensi masing-masing 9 orang $(39,1 \%)$. Sedangkan dari status gizi sebagian besar kategori normal sebanyak 14 orang (60,9\%). Sedangkan untuk rerata suhu tubuh petani dalam batas normal yaitu $36,57^{\circ} \mathrm{C}$. Suhu tubuh paling rendah $36,3{ }^{\circ} \mathrm{C}$ dan paling tinggi $37,2^{\circ} \mathrm{C}$. Dari hasil confidence interval $95 \%$ diyakini bahwa suhu tubuh petani berkisar antara $36,50{ }^{\circ} \mathrm{C}$ sampai dengan $36,65^{\circ} \mathrm{C}$. Pemeriksaan nadi juga diketahui bahwa rerata nadi normal yaitu $87,74 \mathrm{kali} / \mathrm{menit}$. Nadi paling rendah $80 \mathrm{kali} / \mathrm{menit}$ dan paling tinggi 92 $\mathrm{kali} / \mathrm{menit}$. Hasil confidence interval $95 \%$ diyakini bahwa frekuensi nadi berkisar antara 86,4 kali/menit sampai dengan $89 \mathrm{kali} / \mathrm{menit}$. Untuk frekuensi pernapasan diketahui rerata berada dalam batas normal yaitu 19,48 kali/menit. Frekuensi napas paling rendah $16 \mathrm{kali} / \mathrm{menit}$ dan paling tinggi $22 \mathrm{kali} / \mathrm{menit}$. Hasil confidence interval $95 \%$ diyakini bahwa frekuensi pernapasan 
berkisar antara 18,72 kali/menit sampai dengan 20,24 kali/menit. Berat badan diketahui rerata sekitar 58,22 kg. Berat badan paling rendah yaitu $40 \mathrm{~kg}$ dan paling tinggi $70 \mathrm{~kg}$. Hasil confidence interval 95\% diyakini bahwa berat badan berkisar antara 54,97 kg sampai dengan 61,47 kg. Tinggi badan diketahui rerata sekitar $163,13 \mathrm{~cm}$. Tinggi badan paling rendah $150 \mathrm{~cm}$ dan paling tinggi $176 \mathrm{~cm}$. Hasil confidence interval 95\% diyakini bahwa tinggi badan berkisar antara 160,67 $\mathrm{cm}$ sampai dengan 165,60 $\mathrm{cm}$. Hasil pemeriksaan gula darah acak diketahui bahwa rerata petani mempunyai GDA 117,91 mg/dl. GDA paling rendah $70 \mathrm{mg} / \mathrm{dl}$ dan paling tinggi $292 \mathrm{mg} / \mathrm{dl}$. Hasil confidence interval $95 \%$ diyakini bahwa GDA petani berkisar antara 98,69 mg/dl sampai dengan $137,14 \mathrm{mg} / \mathrm{dl}$ artinya masih dalam batas kisaran normal (Tabel 2).

Tabel 1. Hasil skrining pemeriksaan tekanan darah dan indeks massa tubuh (IMT) petani ( $n=23)$

\begin{tabular}{lll}
\hline Skrining kesehatan & & $\mathrm{n}(\%)$ \\
\hline Tekanan Darah & Normal & $4(17,4)$ \\
& Pre Hipertensi & $9(39,1)$ \\
& Hipertensi Grade 1 & $9(39,1)$ \\
& Hipertensi Grade 2 & $1(4,3)$ \\
Indeks Massa Tubuh (IMT) & Kurus & $2(8,7)$ \\
& Normal & $14(60,9)$ \\
& Kelebihan Berat Badan (Berisiko) & $5(21,7)$ \\
& Kebelihan Berat Badan (Obesitas 1) & $2(8,7)$ \\
\hline
\end{tabular}

Tabel 2. Hasil skrining pemeriksaan suhu, nadi, frekuensi pernapasan, berat badan, tinggi badan, gula darah acak (GDA) petani $(\mathrm{n}=23)$

\begin{tabular}{lccccc}
\hline Skrining kesehatan & Mean & $\begin{array}{c}\text { Standar } \\
\text { Deviasi }\end{array}$ & Minimum & Maksimum & 95\% CI \\
\hline Suhu tubuh & 36,57 & 0,1757 & 36,3 & 37,2 & $36,50-36,65$ \\
Nadi & 87,74 & 2,911 & 80 & 92 & $86,4-89$ \\
Frekuensi pernapasan & 19,48 & 1,755 & 16 & 22 & $18,72-20,24$ \\
Berat badan & 58,22 & 7,519 & 40 & 70 & $54,97-61,47$ \\
Tinggi badan & 163,13 & 5,699 & 150 & 176 & $160,67-165,60$ \\
Gula darah acak & 117,91 & 44,451 & 70 & 292 & $98,69-137,14$ \\
\hline
\end{tabular}

Sebelum kegiatan pendidikan kesehatan, sebagian besar petani mempunyai pengetahuan kurang sejumlah 14 orang $(60,9 \%)$ tentang Green Tobacco Sickness (GTS). Setelah kegiatan pendidikan kesehatan, hampir seluruhnya petani mempunyai pengetahuan baik sejumlah 21 orang (91,3\%) tentang GTS (Tabel 3). Hasil ini menunjukkan bahwa terjadi peningkatan pengetahuan petani sebelum dan sesudah kegiatan pendidikan kesehatan tentang GTS. Artinya bahwa kegiatan pendidikan memberikan dampak terhadap meningkatnya pengetahuan petani khususnya tentang topik GTS. Hasil ini sesuai dengan hasil pengabdian yang menyatakan bahwa terjadi peningkatan pengetahuan siswa remaja tentang bahaya rokok setelah diberikan kegiatan penyuluhan dengan metode yang sama yaitu metode ceramah tanya jawab (Prihatiningsih et al., 2020). Didukung dari hasil pengabdian lainnya yang menemukan bahwa meode ceramah dan leaflet efektif dalam meningkatkan pengetahuan masyarakat tentang rumah sehat (Sukesi et al., 2020).

Tabel 4 menunjukkan bahwa sebelum kegiatan pendidikan kesehatan, sebagian besar petani mempunyai pengetahuan kurang sejumlah 12 orang $(52,2 \%)$ tentang pentingnya penggunaan APD bagi petani tembakau. Hasil ini sesuai dengan hasil pengabdian lain yang menemukan bahwa kebiasaan petani dalam menggunakan APD mayoritas buruk sehingga menyebabkan paparan pestisida semakin tinggi (Suparti, S \& Suparman, 2019). Setelah kegiatan pendidikan kesehatan, hampir seluruhnya petani mempunyai pengetahuan baik sejumlah 20 orang $(87,0 \%)$ tentang pentingnya penggunan APD saat bekerja mengolah tembakau. Hasil pengabdian ini sejalan dengan hasil pengabdian yang menyatakan bahwa pelatihan metode 
ceramah dan diskusi pada kader ksehatan efektif dalam meningkatkan pengetahuan tentang kesehatan ibu dan anak (Kurniawan et al., 2017).

Sebelum kegiatan pendidikan kesehatan dan pendampingan, sebagian besar petani mempunyai perilaku kurang baik dalam menggunakan APD sejumlah 14 orang $(60,9 \%)$ (Tabel 5). Hasil ini sesuai dengan hasil pengabdian lain yang menemukan bahwa kebiasaan petani dalam menggunakan APD mayoritas buruk sehingga menyebabkan paparan pestisida semakin tinggi (Suparti, S \& Suparman, 2019). setelah kegiatan pendidikan kesehatan dan pendampingan, hampir seluruhnya petani mempunyai perilaku penggunaan APD baik sejumlah 19 orang (82,6\%). Hasil ini sejalan dengan hasil pengabdian sebelumnya yang menemukan bahwa pelatihan penggunaan APD pada petani dapat meningkatkan perilaku penggunaan APD pada petani sebagai upaya penceahan paparan pestisida terhadap tubuh (Ambarwati, $\mathrm{N}$. V, Sinaga, E. M \& Gultom, 2020). Didukung hasil pengabdian lainnya yang menyatakan bahwa pelatihan keselamatan dan kesehatan kerja (K3) juga penting dilakukan pada kelompok petani karena berdasarkan analisis situasi diketahui bahwa masih banyak petani yang belum mengetahui tentang pentingnya K3 dalam bekerja agar terhindar dari penyakit saat bekerja (Giri, 2016). Sama dengan hasil pengabdian lain menemukan juga bahwa kesadaran petani akan keselamatan dan kesehatan kerja khususnya dalam membuat bahan-bahan pestisida yang aman juga belum optimal sehingga pelatihan pembuatan pestisida yang aman pada petani dilakukan dan efektif dalam meningkatkan pengetahuan dan perilaku petani dalam menerapkan perilaku kesehatan dan keselamatan kerja (Phuspa, S.M \& Rosanti, 2017).

Tabel 3. Pengetahuan petani sebelum dan sesudah pendidikan kesehatan tentang GTS

\begin{tabular}{lcc}
\hline \multicolumn{1}{c}{ Pengetahuan } & Frekuensi & Persentase (\%) \\
\hline Sebelum Pendidikan Kesehatan & 0 & 0 \\
Baik & 9 & 39,1 \\
Cukup & 14 & 60,9 \\
Kurang & & \\
Sesudah Pendidikan Kesehatan & 21 & 91,3 \\
$\quad$ Baik & 2 & 8,7 \\
Cukup & 0 & 0 \\
Kurang & & \\
\hline
\end{tabular}

Tabel 4. Pengetahuan petani sebelum dan sesudah pendidikan kesehatan tentang pentingnya penggunaan APD saat bekerja

\begin{tabular}{lcc}
\hline \multicolumn{1}{c}{ Pengetahuan } & Frekuensi & Persentase (\%) \\
\hline Sebelum Pendidikan Kesehatan & 2 & 8,7 \\
Baik & 9 & 39,1 \\
Cukup & 12 & 52,2 \\
Kurang & 20 & 87,0 \\
Sesudah Pendidikan Kesehatan & 3 & 13,0 \\
Baik & 0 & 0 \\
Cukup & & \\
Kurang & & \\
\hline
\end{tabular}

Tabel 5. Perilaku penggunaan APD petani sebelum dan sesudah pendidikan kesehatan dan pendampingan

\begin{tabular}{lcc}
\multicolumn{1}{c}{ Pengetahuan } & Frekuensi & Persentase (\%) \\
\hline Sebelum Pendidikan Kesehatan & 1 & 4,3 \\
Baik & 8 & 34,8 \\
Cukup & 14 & 60,9 \\
Kurang & & \\
Sesudah Pendidikan Kesehatan & 19 & 82,6 \\
Baik & 4 & 17,4 \\
Cukup & 0 & 0 \\
Kurang & & \\
\hline
\end{tabular}




\section{KESIMPULAN DAN SARAN}

Berdasarkan hasil kegiatan pendidikan kesehatan yang telah dilakukan maka dapat disimpulkan bahwa pengetahuan petani tentang Green Tobacco Sickness (GTS) meningkat lebih baik setelah diberikan pendidikan kesehatan. Begitu juga pengetahuan petani tentang pentingnya penggunaan alat pelindung diri (APD) saat bekerja mengolah tembakau meningkat lebih baik setelah diberikan pendidikan kesehatan. Selain itu perilaku petani dalam menggunakan alat pelindung diri saat bekerja mengolah tembakau menjadi lebih baik setelah kegiatan pendidikan kesehatan dan pendampingan penggunaan APD. Dengan demikian maka disarankan kepada petani untuk selalu menggunakan APD saat bekerja mengolah tembakau agar terhindar dari GTS. Sedangkan bagi petugas kesehatan terutama di Puskesmas disarankan untuk secara rutin melakukan penyuluhan kesehatan kepada kelompok petani tembakau tentang pentingnya APD untuk mencegah GTS serta memantau secara rutin perilaku penggunaan APD petani agar terhindar dari GTS.

\section{UCAPAN TERIMA KASIH}

Terima kasih kami sampaikan kepada Lembaga Penelitian dan Pengabdian kepada Masyarakat (LPPM) Universitas Muhammadiyah Jember yang telah memberikan bantuan atas terselenggaranya kegiatan pendidikan kesehatan ini.

\section{DAFTAR PUSTAKA}

Ambarwati, N. V, Sinaga, E. M \& Gultom, E. (2020). Penyuluhan usaha proteksi diri terhadap pemaparan pestisida pada petani di Desa Semangat Kecamatan Merdeka Kabupaten Karo. Jurnal Abdimas Mutiara, 1(2), 177-183.

Giri, M. K. W. (2016). Pelatihan keselamatan dan kesehatan kerja (k3) pertanian di desa antapan, kecamatan baturiti, kabupaten tabanan. Jurnal Widya Laksana, 5(1), 47-51.

Kementerian Kesehatan Republik Indonesia. (2015). Situasi kesehatan kerja. Kementerian Kesehatan Republik Indonesia.

Kurniawan, A., Gamelia, E., Sistiarani, C., Kesehatan, J., Fakultas, M., Soedirman, U. J., \& Ibu, K. A. (2017). Efektivitas pelatihan metode ceramah dan diskusi kader kesehatan untuk meningkatkan pengetahuan tentang kesehatan ibu dan anak di Puskesmas I Baturraden. Jurnal Kesmas Indonesia, 9(1), 23-33.

Ministry of Health. (2018). Kenali dan Cegah GTS (Green Tobacco Sickness). 18. http://p2ptm.kemkes.go.id/uploads/VHcrbkVobjRzUDN3UCs4eUJ0dVBndz09/2018/11/Ke nali_dan_Cegah_GTS_Green_Tobacco_Sickness.pdf

Phuspa, S.M \& Rosanti, E. (2017). Penyuluhan mengenai penggunaan pestisida yang baik dan benar di Desa Jurug Kecamatan Sooko Kabupaten Ponorogo. International Journal of Community Service Learning, 1(2), 95-100.

Prihatiningsih, D., Luh, N., Devhy, P., Purwanti, I. S., Wayan, N., \& Bintari, D. (2020). Penyuluhan bahaya rokok untuk meningkatkan kesadaran remaja mengenai dampak buruk rokok bagi kesehatan di smp tawwakal denpasar. Jurnal Pengabdian Kesehatan. 3(1), 5058 .

Rokhmah, D. (2014). Insidens dan perilaku pencarian penyembuhan (health seeking behaviour) 
green tobacco sickness (GTS) pada petani tembakau. http://repository.unej.ac.id/

Sukesi, T. W., Maurizka, I. R., Pratiwi, R. D., \& Kahar, M. V. (2020). Peningkatan pengetahuan rumah sehat dengan metode ceramah dan leaflet di Dusun Modalan. Jurnal Pemberdayaan: Publikasi Hasil Pengabdian kepada Masyarakat. 4(2), 183-190.

Suparti, S \& Suparman, U. (2019). Kesehatan tubuh petani lebih penting dari kesehatan tanaman. Jurnal Implementasi Pengabdian Masyarakat Kesehatan (JIPMK), 1(1), 20-25.

Ye, M., Beach, J., Martin, J. W., \& Senthilselvan, A. (2013). Occupational pesticide exposures and respiratory health. 6442-6471. International Journal of Environmental Research and Public Health. https://doi.org/10.3390/ijerph10126442 